Fecha de recepción: marzo 2021

Fecha de aceptación: abril 2021

Versión final: mayo 2021

\section{El camino de las heroínas en tiempos de ciencia ficción}

María Sara Müller ${ }^{(1)}$

Resumen: El 2020 no fue nuestro mejor año. Nunca habíamos vivido en estado de cuarentena global, nunca habíamos visto a los países más ricos tan vulnerables, nunca habíamos temido de modo tan acuciante por nuestros seres queridos. Nos enfrentamos -continuamos en esa batalla- al COVID-19: el "enemigo invisible". De la noche a la mañana naufragamos en un escenario propio de la ciencia ficción. El cariz premonitorio de Virus (Sung-su Kim, 2013), Contagion (Steven Soderbergh, 2011) y Epidemia (Wolfgang Petersen, 1995) se hizo carne. El miedo a la muerte y a la enfermedad escapó de la "silver screen" y el mundo cambió para siempre.

Fue la ciencia ficción -independizada del relato fantástico- la que a lo largo de la historia se nutrió del pánico a la invasión, la hambruna, el contagio, las consecuencias de la actividad nuclear, los bombardeos, las catástrofes inesperadas. Todos relatos donde la muerte ya no espera "al final de la vida sino que se precipita por proximidad" (Rodríguez Alzueta, 2020, p.81). Al igual que otros géneros y subgéneros cinematográficos encontró su origen en la literatura, y vale subrayar que la primera obra reconocida como tal es Frankenstein, novela escrita por una mujer (Aldiss, 1973). Con el advenimiento del cine, el enamoramiento fue inmediato. Desde Le Voyage dans la Lune (Georges Méliès, 1902) la ciencia ficción se ha establecido en la pantalla grande $-\mathrm{y}$ chica- $\mathrm{y}$ no deja de expandirse y diversificarse.

Sin embargo, también hay que decir que la representación de la práctica científica no ha sido una de las más mimadas por el cine. El tratamiento de la tecnociencia "parece dotar a guionistas y directores de cierta patente de corso para presentar, a menudo, una imagen de la ciencia que nada se corresponde con la realidad" (Moreno Lupiáñez, 2007, p.1). Y ahí desfilan los estereotipos del "alquimista aprendiz de brujo", el "genio despistado", o el "científico loco, malo y peligroso" (Haynes, 2003).

Si esta es la imagen recurrente del hombre dedicado a la ciencia, ¿qué quedará para la mujer en un género donde "lo masculino" ha mantenido un lugar de privilegio? Cineastas y películas de todas las épocas, empezando por Fritz Lang y su autómata en Metrópolis (1927), pasando por The Stepford wives (Frank Oz, 2004), incluso Blade Runner (Ridley Scott, 1982) y muchos ejemplos más, se han fascinado por presentar a la mujer como creación científica, "fantasía propia de una sociedad patriarcal que sueña con someter a la mujer al dictado de los hombres" (Dos, 2010, p.32). Difícil búsqueda será la de eruditas investigadoras, precisas y objetivas con un rol protagónico, donde los descubrimientos se dan a partir de su intelecto, como estandartes de soluciones matemáticas, físicas, médicas. Mujeres como sujeto simbólico y no como objeto. 
"Durante el siglo XX el cine se constituyó en un medio que masificó valores, comportamientos, ideologías y relatos sobre la sociedad urbana y la modernización de las culturas, con la capacidad de incidir en la configuración del sentir y pensar" (Acosta Jiménez, 2018, p.52). Con esta premisa presente y comprendiendo el cine como documento, lugar de la memoria y del imaginario colectivo, trataremos de acercarnos a los diferentes "fines del mundo" que nos ofreció el séptimo arte para dimensionar el lugar de la heroína de la ciencia ficción. Porque después de todo, el coronavirus también "nos arroja al gran ruedo en el cual importan sobre todo los grandes debates societales; cómo pensar la sociedad de aquí en más" (Svampa, 2020, p.18).

Palabras claves: cine - ciencia ficción - mujeres objeto - estereotipos de la ciencia - películas premonitorias - heroínas científicas.

[Resúmenes en inglés y portugués en las páginas 114-116]

(1) María Sara Müller es Doctoranda del Programa Interuniversitario de Doctorado en Educación (UNTREF, UNSAM, UNLA). Diplomada en Educación Permanente de Jóvenes y Adultos (UMET-2019). Profesora en Docencia Superior (UTN-2014). Magíster y Especialista en Educación, lenguajes y medios (UNSAM-2013). Licenciada en Comunicación Audiovisual (UNSAM-2001). Productora y Directora de radio y televisión (ISER1996). Docente de la Universidad de Palermo de Taller de Creación III. Docente titular de la Universidad de Belgrano de la carrera Producción y Dirección de TV, Cine y Radio. Docente del CENS 69. Directora del CENS 26 (secundario para adultos dependiente del Ministerio de Educación del Gobierno de la Ciudad).

\section{Introducción}

El coronavirus afecta solo a China, por la sopa de murciélagos. Llegan audios de WhatsApp que auguran el apocalipsis. Italia se deja estar entonando Bella ciao. España no la ve venir. Boris dice que Gran Bretaña prioriza la economía; Bolsonaro, que es una gripecita, pero se contagia y lo desmiente. Se contagia también Boris. Trump discrimina again: apoda al COVID-19 «virus chino». Continúan matando mujeres por su condición de mujeres. Golpean la puerta en Argentina, y es el coronavirus. Medida preventiva: todo el mundo adentro. [...] Y aquí comienza a desorganizarse lo cotidiano y a inaugurarse una forma que -hasta el día de hoy- no ha tenido un solo precedente en nuestra historia. (Méndez, 2020, p.244 cursivas del original) 
El 2020 no fue nuestro mejor año. Nunca habíamos vivido en estado de cuarentena global, nunca habíamos visto a los países más ricos tan frágiles, nunca habíamos temido por la salud de nuestros padres y abuelos de forma tan acuciante, nunca nos habíamos hecho tantas preguntas que -a corto plazo al menos- no tuvieran respuesta. El COVID-19, "el enemigo invisible", con su aplastante incertidumbre, nos instaló en "modo pausa" donde proyecciones de ningún tipo -desde económicas, políticas, sanitarias, hasta las más cotidianas- tenían cabida. Nos vimos, de la noche a la mañana, naufragando en un escenario de ciencia ficción. El miedo a la muerte y a la enfermedad escapó de la "silver screen" y el mundo cambió para siempre.

La ciencia ficción cinematográfica a lo largo de la historia se nutrió del pánico a la invasión extraterrestre, la hambruna, el contagio, las consecuencias de la actividad nuclear, los bombardeos, las catástrofes inesperadas. Todos relatos donde la muerte ya no espera "al final de la vida sino que se precipita por proximidad” (Rodríguez Alzueta, 2020, p.81). Al igual que otros géneros y subgéneros encontró su origen en la literatura, y con el advenimiento del cine, el flechazo fue inmediato, amor a primera vista.

Si bien este es un texto que examinará el cine como medio, tendrá contactos frecuentes con "lo que nos pasó", lo impensable: La Pandemia con mayúsculas. Porque es lo que nos interpela todavía, porque creemos imprescindible la reflexión colectiva -o intentarla al menos- sobre lo que podemos construir hacia adelante, como si la cuarentena hubiera sido una bisagra que nos invitara a meditar detenidamente sobre "lo que vendrá". Ya nada puede ser igual o no debería serlo.

Comenzaremos con una conceptualización sobre el género de ciencia ficción -tarea poco sencilla-, y para explicitar su relación con los procesos sociohistóricos focalizaremos en el discurso apocalíptico y post apocalíptico. Luego, recorreremos algunas representaciones de la práctica científica -que no han sido de las más mimadas por el cine, hay que decirlo-, y los estereotipos cinematográficos de hombres y mujeres de ciencia. También nos dedicaremos a la mujer como creación, las múltiples mujeres-objeto que pueblan las pantallas, para irnos acercando a la dimensión de las heroínas científicas propiamente dichas y el "primer contacto". Para finalizar, las epidemias tendrán su apartado propio con aquellas películas, que comprendemos, con un cariz premonitorio.

La premisa transversal que habitará el escrito será que el cine se manifiesta como documento, lugar de la memoria y del imaginario colectivo. "Durante el siglo XX el cine se constituyó en un medio que masificó valores, comportamientos, ideologías y relatos sobre la sociedad urbana y la modernización de las culturas, con la capacidad de incidir en la configuración del sentir y pensar" (Acosta Jiménez, 2018, p.52). Es decir, nuestro ser sentipensante ha sido amasado -en parte- por el medio con el que hemos crecido, pasado horas y horas delante de su pantalla, que nos ha deleitado y nos ha "formado" como sujetos además de audiencias. 


\section{Desarrollo}

\section{Esa estrella era mi lujo}

Lo que perfora, de manera radical nuestra existencia, es la erosión de la confianza en nuestra propia capacidad, en tanto especie, de conservar la vida. Se ve que no bastaron, para nuestros propios recursos adaptativos, ni las lecturas atentas de Virilio, de Beck, de Luhmann, entre otros, ni nuestros imaginarios formateados en la literatura y el cine distópico de ciencia ficción; no bastaron, parece, todos los productos de la cultura mediática que década tras década intentaron prepararnos. (Valdettaro, 2020, p.151)

La ciencia ficción presenta grandes dificultades a la hora de ser dimensionada e intentar localizar su origen literario suele ser objeto de discusión. Autores como Freixas y Bassa (1993) la identifican como subgénero del fantástico con una definición muy lúcida.

Consideramos que la ciencia ficción, inscrita en el Fantástico, comporta una irrupción de lo imaginario en lo real utilizando la ciencia como coartada de la fantasía, provocando la transformación del verosímil en un referente tanto eminente como pretendidamente científico que cumplirá, en ambos supuestos, un rol mítico. (Freixas y Bassa, 1993, p.31)

A su vez, Monroy (2008) sostiene que la ciencia ficción como género se funda gracias a Hugo Gernsback, por ser quien acuñara el término "scientifiction" en su edición de la primera revista especializada: Amazing Stories en 1926. Por otro lado, Aldiss (1973) señala que Frankenstein de Mary Shelley escrito en 1818, es la primera obra que responde a este género por los acontecimientos en torno a los cuales gira la trama, y porque el mito es potenciado por lo "creíble" donde la ciencia juega un rol fundamental. (Un paréntesis para mencionar otra obra de Shelley El último hombre de 1826, en la que retrata una sociedad futura del siglo XXI que ha sido arrasada por una terrible plaga originaria de Asia).

Así, "lo científico" comienza a sustituir a "lo mágico" y "con el paso del tiempo, poco a poco este subgénero ha ido escalando en popularidad, adquiriendo el estatus de un verdadero género individual" (Olagüe, 2018, p.11).

La misma dificultad para establecer el origen literario se traslada al terreno cinematográfico: es difícil definir unívocamente la primera película. Hay quienes se inclinan por Le Voyage dans la Lune (Viaje a la luna, Georges Méliès, 1902), otros por Metrópolis (Fritz Lang, 1927).

Tras identificarse un género, su primera aparición en un filme se considera como un prototipo genérico, fruto de la unión entre una forma preexistente y una nueva tecnología. El nuevo género, entonces, se desarrolla, madura y goza de una carrera estable, para entrar luego en una vejez reflexiva que desemboca en su muerte. Normalmente, los críticos dan por sentado que los géneros cinematográficos se toman prestados de géneros ya existentes en otros medios. (Altman, 2000, p.55) 
De la cita anterior queremos extraer dos ideas claves que constituirán un eje bifronte, necesario a nuestro entender, para apreciar la ciencia ficción en el cine. El primer eje, generalizable, sobre el error de recurrir a prototipos aferrados a géneros no fílmicos ya existentes para situar los inicios. "Esta actitud aplaza indefinidamente toda explicación de tales orígenes" (Altman, 2000, p.56). El cine no toma en préstamo ingredientes de una sola fuente extracinematográfica que actúa como ascendiente directo, sino que incorpora "de forma aparentemente fortuita materiales de distintos géneros desvinculados entre ellos" (ibíd., p.60). Pero incluso en los casos en que un género tiene una existencia anterior en otros ámbitos, para la concreción de su homónimo cinematográfico siempre es necesaria una recreación (Altman, 2000).

El segundo eje, que nos enfrenta a la singularidad de la ciencia ficción como clase de texto genérico -que se establece como discriminable de otros por sus elementos temáticos, retóricos y enunciativos-, es la particularidad con la que ha logrado adaptarse a las preocupaciones de la humanidad sin perder determinada estabilidad. En este sentido, el debate se establece con aquellos que refieren que los géneros tienen un esquema de desarrollo antropomórfico que los lleva obligadamente a la autodestrucción, y donde una observación minuciosa de las cuestiones históricas puede poner en jaque los cimientos sobre los que se asientan (Altman, 2000).

Si algo caracteriza a la ciencia ficción es su versatilidad. Gilks y Allen (2003) diferencian trece subgéneros. Sin embargo, hay que decir que la disposición en el paper de estos autores -que es la que nosotros retomamos-, no implica orden de importancia, aparición histórica, peso icónico o cantidad de obras. Aclarado esto, como subgéneros tenemos: a) Apocalíptico o post-apocalíptico. El foco está puesto en el fin del mundo y en cómo la humanidad enfrenta las secuelas de ese holocausto; b) Géneros cruzados. La ciencia ficción demuestra su carácter híbrido al mezclarse con otros géneros: fantástico, romántico, misterio, suspenso o western; c) Ciberpunk. Presenta un escenario sombrío, mecanicista y futurista, repleto de hackers y seres mitad computadora-mitad humanos. Incluso los personajes podrían estar viviendo en un contexto virtual; d) Primer contacto. Focaliza en el encuentro entre humanos y alienígenas que puede ocurrir en la Tierra, en el espacio o en otro planeta; e) Ciencia ficción dura. La ciencia y la tecnología son fundamentales para la trama y los problemas comienzan cuando algo no funciona como debería; f) La ciencia ficción light o de humor. Se burla y satiriza las convenciones del género; g) Ciencia ficción militar. Analiza el combate en ubicaciones futuras (colonias espaciales), contra una variedad de oponentes: humanos modificados, extraterrestres, máquinas, etc., con armamento de alta tecnología. Explora tanto el heroísmo como la carnicería de la guerra; h) Ciencia ficción-futuro cercano. Tiene lugar en la actualidad o en las próximas décadas, los elementos del entorno deben ser familiares para el espectador. La ciencia aplicada puede estar aún en desarrollo: nanotecnología, ingeniería genética, etc. i) Fantasía científica / fantasía futura. Popular en las décadas de 1930 y 1940, altera, rompe o ignora leyes o teorías científicas conocidas; j) Slipstream. Especula sobre el presente o un futuro muy próximo con alto grado de surrealismo; k) Ciencia ficción soft / sociológica. Impulsada por los personajes -su psicología y sus interacciones- con énfasis en el cambio social. La tecnología desempeña un papel importante, y el acento está en cómo afecta a los individuos o grupos sociales. 1) Space Opera. Aventura en las profundidades del espacio o en un planeta 
distante, que a menudo implica a los buenos disparándole a los malos (alienígenas, robots, otros humanos); m) Viaje en el tiempo. Los personajes viajan al pasado o al futuro, o son visitados por viajeros de cualquier extremo del espectro. Una variante de este subgénero son los "universos alternativos", en el que cada cambio en la corriente temporal genera una nueva vertiente o nuevo universo.

Como consideramos las películas como "dispositivos culturales que recrean y resignifican elementos simbólicos, espaciales, temporales y materiales que brindan indicios o huellas sobre el acontecer de las sociedades" (Acosta Jiménez, 2018, p.52), nos resulta pertinente una breve línea de tiempo en pos de visibilizar la correspondencia entre la ciencia ficción en el cine y determinados procesos históricos y sociales emblemáticos. Es decir, la ciencia ficción no solamente no se ha visto restringida por ese devenir, sino que aparentemente se ha fortalecido, rasgo que a la vez le permitiría una proyección futura con innumerables posibilidades.

A modo de ejemplo que explicite esta adaptabilidad a la que referimos, y solamente tomando una pequeña porción del gran bufé que nos ofrece el género: la acción nuclear que podría desembocar en el Apocalipsis, seguiremos la organización por décadas de Del Molino García (2003).

Según este autor, podemos ubicar los orígenes del discurso apocalíptico entre 1939 y 1945, coincidente con el inició del Proyecto Manhattan. Las bombas desarrolladas serían lanzadas sobre Hiroshima y Nagasaki. Luego del bombardeo norteamericano a Japón, justificados signos de miedo colectivo hacia la nueva forma de energía y su destrucción devastadora tomaron las pantallas.

Para los años 50's (1949-1959) "la reacción soviética no se hizo esperar y en 1949 se hicieron poseedores de su primera bomba nuclear. La carrera por el armamento atómico entre las dos potencias instauró un nuevo sistema internacional basado en el equilibrio del terror nuclear" (ibíd., p.9 cursivas del original). El discurso del miedo se instala en las sociedades europeas y estadounidenses al tiempo que la Guerra Fría. De más está decir que "la abundante filmografía de [...] la maquinaria de Hollywood trabajó concienzudamente para fijar un significado: los rusos eran malvados" (Menéndez y Medina, 2006, p.57). La derivación y ampliación temática llevó a que muchas películas de la época imaginaran "la mutación sufrida por diferentes seres vivos expuestos a la radiación de las pruebas nucleares realizadas por el ser humano convirtiéndolos en un peligro para la humanidad" (Del Molino García, 2003, p.9). Por nombrar algunos ejemplos de la década: The Beast from 20.000 Fathoms (El monstruo de tiempos remotos, Eugene Lourie, 1953), Gojira (Japón bajo el terror del monstruo, Ishirô Honda, 1954 - destacamos esta película en particular como icónica, además de ser la primera hecha por el único país que vivió en carne propia ese horror), Them! (La humanidad en peligro, Gordon Douglas, 1954), The day the world ended (El día del final del mundo, Roger Corman, 1955), The Incredible Shrinking Man (El increíble hombre menguante, Jack Arnold, 1957).

Un nuevo periodo apocalíptico podría ubicarse entre 1960 y 1972 con la reformulación de la Guerra Fría. Las crisis de Berlín y Cuba forjaron la posibilidad real de un enfrentamiento atómico entre EEUU y Rusia. 
$\mathrm{Al}$ igual que en la década precedente, la industria cinematográfica de Ciencia Ficción se hizo eco del discurso del miedo atómico y la amenaza de holocausto nuclear que supone la política de paridad llevada a cabo por las dos superpotencias mundiales. Desarrolló una iconografía [...], sin abandonar las producciones de seres vivos mutantes, retratando la vida en el planeta inmediatamente después de una guerra con armas atómicas. (Del Molino García, 2003, p.10)

Y así, aparecen: On the Beach (La hora final, Stanley Kramer, 1959), The Time Machine (El tiempo en sus manos, George Pal, 1960), The day The Earth caught fire (El día en que la tierra se incendió, Val Guest, 1961), Dr. Strangelove, or how I learned to stop worrying and love the bomb (¿Teléfono rojo? Volamos hacia Moscú, Stanley Kubrick, 1964), Planet of the Apes (El planeta de los simios, Frankilin J. Shaffner, 1968), The Omega Man (El último hombre... vivo, Boris Sagal, 1971).

Con el primer instrumento bilateral entre EEUU y Rusia que limitaba el uso de armas atómicas, se inicia un periodo de distensión entre 1972 y 1979. "No es casual que al disminuir el discurso del miedo al enfrentamiento bélico también disminuyeran la iconografía y las representaciones cinematográficas apocalípticas" (ibíd., p.12). Sin embargo, la proliferación de centrales nucleares con los subsecuentes accidentes que incluyeron nubes radioactivas y fugas de uranio, cambiaron el temor al bombardeo por el mal uso de la energía nuclear civil, y los espectadores comenzaron a visualizar soledades posnucleares. Algunos ejemplos pueden ser: Zardoz (John Boorman, 1974), The Ultimate Warrior (Nueva York, año 2012, Robert Clouse, 1975), The China Syndrome (El síndrome de China, James Bridges, 1975).

La era Reagan (entre 1980 y 1989) y el nuevo programa de rearme estadounidense catapultó de nuevo el terror. "El discurso del miedo apocalíptico resurgió en la cultura de masas y en el imaginario colectivo occidental iniciándose una nueva etapa iconográfica del desastre" (ibíd., p.12). La hipotética guerra-mundial-nuclear vuelve a estar cercana, y en un futuro próximo sus consecuencias podrían sumir a los ciudadanos comunes en desiertos violentos donde todo es competencia por los recursos para la supervivencia, desde el agua hasta el petróleo. Le Dernier Combat (Kamikaze 1999, Luc Besson, 1983), Testament (Testamento final, Lynne Littman, 1983), Mad Max 2 (Mad Max 2, el guerrero de la carretera, George Miller, 1981) son algunos exponentes.

La caída del muro de Berlín en 1989 anunciaba el fin de la construcción simbólica propia de la tradición apocalíptica. Sin embargo, la década de 1980 sería una de las más prolíficas en cuanto a películas de ciencia ficción. Directores como Steven Spielberg, James Cameron, Tim Burton, Ridley Scott, David Cronenberg o David Lynch se deciden por abordar temáticas de la sci-fi. "El género toma un camino mucho menos crítico, volviendo a sus orígenes, más ligado al puro entretenimiento y espectacularidad" (Carrasco Carrasco, 2010 citado por Olagüe, 2018, p.16-17).

El cine en general y el género de ciencia ficción en particular, se encuentran estrechamente ligados a las preocupaciones sociales. Todas estas afectan directa e indirectamente la forma de contar historias. Los grandes miedos -al igual que los deseos- terminan proyectados en las pantallas, desde donde miramos al futuro desde el presente creando "un espacio en el que preguntarse qué podría ocurrir bajo unas determinadas circunstancias" 
(Olagüe, 2018, p.13). Pero a la vez, y desde una mirada menos sentimental y más realista, deberíamos comprender con claridad prístina que cuando nos abandonamos a disfrutar una película, el lenguaje audiovisual por medio de su capacidad de representación otorga significado a las imágenes al tiempo que se establece como tecnología de poder. El cine, en definitiva, es una usina de pensamiento (Menéndez y Medina, 2006; Cambra Badii, 2018).

\section{Vencedores vencidos}

Pandemia: Enfermedad epidémica que se extiende a muchos países o que ataca a casi todos los individuos de una localidad o región. Ejemplo: "Una pandemia de corona virus". Etimología: pan (totalidad) y dêm- (pueblo), que significa primero 'el pueblo entero'. [...] Reflexioné sobre el rol de la ciencia, de los científicos y científicas, desde su rol social. De cómo íbamos a intervenir sobre el avance de un virus, de un avance pandémico y qué significaba eso. Ciertamente me hice (y me hago) más preguntas que aseveraciones. (Bilbao, 2020, p.190)

El cine -además de otros medios- ha contribuido históricamente a fijar determinadas imágenes en el imaginario colectivo sobre la práctica científica, que no suelen ser muy halagadoras. "La imagen popular de la ciencia, de los científicos y del entorno donde realizan su actividad (laboratorios) se nutre de los mitos creados por la ficción, reflejo, a su vez, de las prevenciones y recelos que la actividad científica suscita" (Skal, 1998; José, 2000 citados por Moreno Lupiáñez, 2007, p.4). La percepción por parte de la sociedad de la figura del científico y de su actividad debe más a los míticos Frankenstein, Moreau, Fausto o Jekyll que a las personas reales.

Christidou (2010) recopila varias investigaciones que ilustran cómo son vistos los científicos. Las conclusiones de todos los artículos coinciden: son exclusivamente hombres, de mediana edad, calvos o con pelo a lo Einstein, barbados y con anteojos. Su personalidad es excéntrica y antisocial. El vestuario incluye guardapolvo -el color puede variar, pero por lo general es blanco-. Desarrollan su trabajo en laboratorios secretos -muchas veces sótanos o lugares alejados- rodeados de tubos de ensayo, mecheros Bunsen, frascos y botellas con contenidos indeterminables. Toman notas, repasan libros, y un día por fin gritan: “¡Lo descubrí!” (el síndrome de Eureka).

En este sentido, Haynes (2003) define siete estereotipos de científicos que podemos hallar en la narrativa occidental de los cuales el cine se ha alimentado:

1. the "evil alchemist"; 2 . the "noble scientist" as hero or savior of society; 3 . the "foolish scientist"; 4. the "inhuman researcher"; 5. the "scientist as adventurer"; 6. the "mad, bad, dangerous scientist"; 7. the "helpless scientist", unable to control the outcome of his or her work. (p.244)

Según la autora, el "alquimista malvado" o "aprendiz de brujo" a pesar de su mala reputación termina fascinando "because it promised fabulous wealth, power, and longevity" (Haynes, 2003, p.244). Todo está permitido en su campo de experimentación: la búsqueda 
de la piedra filosofal, el elixir de la eterna juventud, la máquina del movimiento perpetuo, la oscilación del átomo o concretar el sueño del humúnculo. "Faust or, more frequently, Frankenstein to condemn not only experiments that have misfired but new research that might prove dangerous" (ibíd. cursivas del original). Este maniático obsesivo, persigue un objetivo intelectual egoísta de aspectos diabólicos. Una encarnación reciente refiere al bioquímico siniestro que produce nuevas especies mediante ingeniería genética (Moreno Lupiáñez, 2007).

El "científico noble" comparte sus conocimientos con el mundo, sin importar las fronteras políticas ni geográficas. Tiene un equipo de investigación porque no persigue riquezas ni fama individual. Sus descubrimientos apuntan directamente al beneficio de toda la humanidad.

With few exceptions, though, the noble scientist in the twentieth century is less likely to be a leader of society than a victim, protesting against immoral activities. This was a common theme during and immediately after World War II in novels and plays in which peace-loving scientists refused, or were unwillingly forced, to work in weapons production or military intelligence. The theme of the scientist refusing to do what was popularly believed to be his patriotic duty became more controversial during the Cold War, when the trials of the atom spies gave rise to numerous analyses of the moral questions involved, sometimes suggesting that the person who gives away scientific secrets to the enemy is the truly moral scientist. (Haynes, 2003, p.246-247)

El "científico tonto" o "despistado" suele ser caricaturizado al obsesionarse por cosas triviales, luce desarreglado y no cuida su aseo personal. Frecuentemente es embaucado por los vendedores de "maravillas". “This stereotype has reappeared repeatedly in more or less harmful guise” (ibíd., p.247).

El "investigador inhumano" surge del "European romanticism, provoked in part by reaction against the scientific materialism of the Enlightenment, generated perhaps the most enduring scientist stereotype: that of the inhuman researcher who has sacrificed his or her emotions and human relationships" (ibíd., p.248-249). Es decir, sufre los efectos del aislamiento voluntario. Mantiene un optimismo ingenuo con respecto al conocimiento y a sus descubrimientos, ya que según él siempre serán utilizados para el bien común. Suele fanatizarse con su proyecto sin importar el costo.

The atomic scientists working on the bomb during World War II and then the Cold War gave added weight to this stereotype with their documented declarations of unconcern about the human cost of their inventions, for the impersonal scientist inevitably shades into the amoral scientist. [...] For our generation, this figure encapsulates the most common of all attributes ascribed to scientists in literature and film—inhumanity. (ibíd., p.249)

El "científico aventurero" es el más atractivo, aunque el más simple de los estereotipos modernos. Surge de la mano de Julio Verne y representa un nuevo optimismo tanto hacia 
la utopía científica como a la maravillosa tradición del viaje. "They carried an unmistakable moral: bravery, endurance, optimism, and reverence for scientific knowledge would overcome all difficulties" (ibíd., p.250).

El "científico loco, malo y peligroso". "The moral characteristics of this figure are not new, having sprung from the alchemist tradition; but twentieth-century writers and filmmakers grafted on a new ruthlessness that soared to the heights of megalomania" (ibíd., p.252). Este estereotipo se ha consolidado gracias al aumento del poder de la ciencia para producir cataclismos a una escala inimaginable. A modo de caso y para dimensionar la extensión, si bien las creaciones de los primeros "científicos locos" habían lastimado a unas pocas personas, los proveedores de la guerra bacteriológica, el gas nervioso o las armas nucleares podrían destruir naciones enteras, y posiblemente la vida del planeta.

El "científico indefenso" es víctima de sus propios descubrimientos. Como manifiesto del romanticismo, rehúsa a hacerse responsable de los desastrosos resultados de sus desarrollos.

In the media, atomic power, robots, germ warfare, genetic engineering, invitro fertilization, organ transplants, gene banks and diminishing biodiversity, cloning, global warming, industrial pollution, mind-changing drugs, artificial intelligence, the Human Genome Project, virtual reality, the Internet, and numerous other projects, real and imagined, are presented in similar terms. The modern heirs of Frankenstein are depicted as being, at best, ignorant of the likely sociological effects of their research and, at worst, quick to suppress any such realization, lest their grants be cut. (ibíd., p.252-253)

Estos estereotipos continúan presentes en las películas actuales. Parecen simples, pero representan ideas complejas y miedos reprimidos que trascienden tiempo, lugar geográfico, raza y cultura. No son solo aplicables a los hombres -aunque los protagonistas de ciencia ficción mayormente lo son-.

Si bien no podemos erradicar estas imágenes de la noche a la mañana, la sugerencia sería prestar atención a su grado de veracidad y su mensaje. Asimismo, varias preguntas quedan pendientes. Se han estudiado estos modelos como lugares comunes, pero poco se ha dicho sobre a qué se dedican los científicos en el cine -sus destrezas, generalmente, no se ciñen a una sola disciplina, suelen ser "todólogos"-. Y otra cuestión válida que nos provoca a la reflexión es qué es "hacer ciencia" desde el punto de vista cinematográfico. A lo largo de la historia, desde las pantallas, hemos recibido múltiples aproximaciones distorsionadas (Levin y Kreimer, 2012).

\section{Ángel en tu soledad}

Sabemos que en el patriarcado-colonial-capitalistaneoliberal las vidas no valen lo mismo. La vida de un hombre blanco, heterosexual, educado, vale más que la de un varón pobre sin acceso a la educación, que seguramente valdrá más que la de un homosexual varón. Sabemos que la vida de una mujer vale me- 
nos que la de ellos tres, si es lesbiana seguramente menos y si se trata de una persona trans menos que menos. El criterio de selección no es arbitrario, tiene que ver con las exigencias del sistema económico y con el rol que se le otorga a cada sujeto dentro de ese sistema. Las vidas de las mujeres valen menos por la desjerarquización del rol social que se les otorga. (Pasquinelli, 2020, p.180)

Como hemos visto, el tratamiento de la tecnociencia "parece dotar a guionistas y directores de cierta patente de corso para presentar, a menudo, una imagen de la ciencia que nada se corresponde con la realidad" (Moreno Lupiáñez, 2007, p.1). Cuando queremos abordar la figura de la mujer en relación con el mundo científico, como sujeto activo, de inteligencia suprema, de fuerza creadora, de profesionalismo indiscutible está lejos de poder equipararse a la presencia del hombre. El cine se ha ocupado escasamente de contar historias protagonizadas por científicas. Sin embargo, un fenómeno llamativo se produce cuando desplazamos la figura de la mujer-científica a la de mujer-creación-científica (Dos, 2010).

La mujer-robot, el erotismo y el amor, son temas recurrentes en las películas de ciencia ficción que propone abundantes reflexiones en torno a los límites entre lo humano y lo tecnológico [...] La fantasía propia de una sociedad patriarcal que sueña con someter a la mujer al dictado de los hombres es recurrente. (ibíd., p.32)

Realizaremos una selección de aquellas películas que entendemos más representativas de la mujer como creación-objeto. De este modo, se traslada al cine la herencia literaria de dos compendios: el primero, que es el hombre el que engendra a la mujer; y el segundo, "el hecho de que la cree más perfecta de lo que la naturaleza habría sido capaz de concebir por sí sola” (Pedraza, 1998 citada por Merás, 2014, p.10). De más está decir, que la mujer artificial creada por un científico varón presenta, en todos los casos, un ideal de belleza femenino ideado desde la mirada masculina.

Metrópolis (Fritz Lang, 1927) propone la aparición de la primera mujer autómata, no solo como eje narrativo sino como personaje que se adelanta a lo que en años posteriores profundizaría el cine de ciencia ficción. Parodia-Futura-Engaño (los tres nombres de la robot-María) instituye un modelo de cyborg femenino amenazante que sería retomado en la Terminatrix de Terminator 3 Rise of machines (La rebelión de las máquinas, Jonathan Mostow, 2003) y en las replicantes de Blade Runner (Merás, 2014).

Andreas Huyssen (2000) fue el primero en advertir el paralelismo entre la vamp (de vampire, «vampiresa») y la maléfica cyborg que desencadena el caos en Metrópolis. En los años veinte la vamp unía el atractivo de una sexualidad desbordante con la frialdad, alentando un prototipo de villana que consolidaría la asociación de la mujer con la máquina. Su ambigüedad y apreciable ausencia de emociones, así como su capacidad para traicionar al héroe [...] particularidad de la vamp- facilitarían la conceptualización de la cyborg como un ente mecánico distinguido con un grado de perversidad específicamente femenino. (ibíd., p.11) 
Se diría que Lang concibe lo femenino como mecánico por definición, una suerte mujer fatal inorgánica. "La mujer máquina seduce y precipita a la perdición a ricos y pobres, hasta que muere en una anacrónica hoguera como una bruja de metal. [...] Restos misóginos que convierten a la mujer emancipada y libre en egoísta y fría" (Pedraza, 2001, p.1). Varias décadas después llegaría The Stepford wives (Bryan Forbes, 1975), que contó con una remake en el año 2004 con el mismo título dirigida por Frank Oz, y protagonizada por Nicole Kidman, Bette Midler y Glenn Close. En su primera versión, los hombres se proponen crear una tropa de "queridas inofensivas" destinadas a atenuar "los perjuicios" que conlleva el matrimonio, "una mujer ideal fabricada por el hombre para el hombre" (Pedraza, 2001, p.3). Así, las mujeres reales son sustituidas por otras cibernéticas. Esta película se presenta como "un ejercicio de misoginia generalizada que fructifica en una suerte de pacto terrorífico entre caballeros para silenciar a sus mujeres" (Dos, 2010, p.32). Lo reiterativo entre la original y la reedición, es que las dos "exponen con humor la inseguridad masculina ante los impulsos emancipadores de sus mujeres, a las que necesitan cosificar" (Merás, 2014, p.22).

Sin embargo, las producciones difieren en el modo de aproximación al conflicto. La de 1975 describe cómo los maridos reemplazan a sus esposas por androides sin mayores aspiraciones que cocinar, limpiar la casa, cuidar a los niños y satisfacerlos sexualmente. En la remake "el quid de la película reside en la posición dominante que han obtenido las mujeres" (ibíd., p.23-24 cursivas del original). Ante la inversión de los "roles tradicionales", cosa que vulnera la autoestima masculina, la función de las cyborg será evitar la competencia en el terreno laboral, económico e intelectual. Lo interesante, como elocuente giro argumental de la nueva de Frank Oz, es que "el artífice de las transformaciones no es un hombre sino una neurocirujana e ingeniera genética [...] que pretendía crear «un mundo perfecto» con «mujeres perfectas»" (ibíd., p.26). Será ella, interpretada por Glenn Close, la responsable de la sustitución de las mujeres por sus dobles autómatas, aunque es necesario decir que este recurso nos hace interrogarnos sobre la intencionalidad y resultado de la crítica.

Blade Runner (Ridley Scott, 1982) manifiesta el fenómeno de la mujer-robot "dotada/diseñada para el erotismo" (Pedraza, 2001, p.1). También es la primera película en explorar el drama de la condición artificial femenina. "En ella se darán cita las dos tipologías de cyborg mujer: [...] el modelo de cyborg obediente y el arquetipo de mujer artificial que no se amilana ante su opresor" (Merás, 2014, p.12).

Por un lado, tenemos el personaje de Rachael -que no sabe que es una "replicante" según la concepción diegética de la película-.

Rachael es decisivo porque, si bien parte de la concepción vamp de la cyborg heredada de Metrópolis, evoluciona a lo largo del filme hasta convertirse en su opuesto. [...] Rachael mantiene un aire anticuado que sigue de forma escrupulosa el estereotipo de femme fatale del cine negro. (Doane, 1990 citado Merás, 2014, p.12).

Este personaje, al enamorarse de su potencial asesino, olvida sus orígenes y su traición no es metafórica: dispara a uno de los suyos sin mucha culpa para salvar la vida del Blade Runner 
(Merás, 2014). Por último, emprenderá la huida junto a su perseguidor como una alianza entre máquinas y humanos. Por otro lado, tenemos a las otras dos replicantes: Pris y Zhora. "Insumisas que, lejos de sucumbir ante los encantos de su cazador, luchan denodadamente contra él" (ibíd., p.15). Se nos presentan como "hembras duras, «modernas» y guerreras, que reciben su merecido sin tardanza" (Pedraza, 1998 citada por Merás, 2014, p.15). Han logrado desembarazarse del propósito para el cual han sido creadas, estar disponibles para la satisfacción sexual masculina. Así, será el control de la sexualidad lo que definirá el rol que desempeñe cada una de estas mujeres artificiales en el argumento de la película.

¿A qué se debe la diferencia en la caracterización de Rachael frente a sus compañeras insurrectas? La respuesta es que aunque Rachael sea una erotizada femme fatale propia del cine negro, se revela como sexualmente inexperta justamente al contrario que las demás cyborgs de la película- y, por lo tanto, en lugar de conducir al héroe a la perdición como le correspondería, le salva. (Jermyn, 2005, p.167).

Varios films quedan en el tintero. El inesperado éxito de Frankenstein (James Whale, 1931), llevó a la Universal a crear toda una franquicia que traería Bride of Frankenstein (La novia de Frankenstein, también dirigida por Whale, 1935), que responde al imaginario de la figura de la mujer muerta "que regresa" popularizada en múltiples obras. "Para el arte y la cultura no es lo mismo un muerto que una muerta. Los hombres muertos abundan en el cine desde los comienzos [...] pero no hay montones de mujeres muertas, sino de concubinas vivas y voluptuosas". (Pedraza, 2009, p.46). En 1965, Dr. Goldfoot and the Bikini Machine (Doctor G. y su máquina de bikinis, Norman Taurog) surge en plena eclosión pop y de la revolución sexual. Si bien la producción es bastante desquiciada, mantiene la premisa de que "detrás de toda mujer-robot se esconde un creador con delirios de grandeza, o léase, un científico loco" (Dos, 2010, p.28). Otro ejemplo podría ser Weird Science (La mujer explosiva, John Hughes, 1985).

Partiendo de dos arquetipos muy simples pero reconocibles para el espectador, la de las sumisas y descerebradas mujercitas construidas para el disfrute masculino o la de hembras tecnológicas convertidas en la pesadilla de los humanos que creían controlarlas, estos filmes tienden a aplacar los componentes más sexistas. [...] Operan jugando con estereotipos femeninos de dominación y sumisión, aunque sin sentirse obligados a desmontarlos. (Merás, 2014, p.29)

Afortunadamente, pareciera haber una apertura para las heroínas de ciencia ficción, que poco a poquito se alejan de las mujeres-objeto. Sería ingenuo pensar que el cine, como industria cultural, no se viera atravesado por lo social: miles de mujeres se manifiestan a diario por sus derechos en todas partes del mundo. Asimismo, la influencia del movimiento \#MeToo -entre otros-, pateó los basamentos de los guiones y cada nueva producción está en el centro de las miradas como si tuviera una diana en la frente. La "forma de organización política, económica, religiosa y social basada en la idea de autoridad y liderazgo del varón, en la que se da el predominio de los hombres sobre las mujeres" (Emakunde, 
2008 citado por Olagüe García, 2018, p.4) comienza a trastabillar y el cine como producto responde a las lógicas del mercado. Esperanzados en que este posicionamiento obsequioso - con tal de agradar a las audiencias y mantenerse en sintonía con los cambios sociales- se sostenga en el tiempo, disfrutamos de estas transformaciones, seguramente obligadas a base de las presiones a las que se ven sometidos los grandes estudios. Al menos por ahora, se viene subvirtiendo la visión instalada de que ser varón es primordial para protagonizar y que solamente ellos ocupan el bando privilegiado en las películas de ciencia ficción. Los personajes femeninos felizmente comienzan a verse revestidos de estimación.

Sin embargo, cabe preguntarnos “ ¿ha cambiado el rol de la mujer científica en los relatos cinematográficos con este incremento de protagonismo, o por el contrario, pese a este paso al frente, sigue presa de los clichés de género?” (Bañuz y Carmona, 2019, p.83). ¿Han logrado las mujeres un reconocimiento como investigadoras, precisas y objetivas con un rol protagónico, donde los descubrimientos se dan a partir de su intelecto, como estandartes de soluciones o continúan siendo accesorias a la trama?

\section{El futuro llegó hace rato}

Ya lo hacía una militancia en gran parte constituida por mujeres que sostienen comedores y merenderos, que defienden a otras en situación de violencia, que cuidan niñes de todo el barrio, que gestionan y pelean en los municipios, que acompañan abortos y que defienden a les pibes de la violencia institucional. La pandemia muestra a esas cuidadoras, y el Estado las reconoce como promotoras comunitarias. (López, 2020, p.76)

La ciencia ficción otorga centralidad tanto a las ventajas como a las inesperadas consecuencias del progreso científico, tanto a la fascinación como a los miedos que genera. Dentro de las posibilidades está que los advenimientos de la ciencia conduzcan al "primer contacto" (Gilks y Allen, 2003) con seres de otros planetas. En este subgénero identificamos dos tendencias en la mayoría de las producciones: una enfocada en la necesidad de supervivencia y la lucha por conseguirla; y otra, más versada en el entendimiento y el interés por la comunicación.

En este apartado recuperaremos a tres heroínas científicas que entendemos representativas del género de ciencia ficción y del encuentro alienígena. Dos abocadas a la comunicación, una a la supervivencia. Para dos el protagonismo femenino es indiscutible, mientras que para la otra hay un lugar privilegiado aunque claramente no protagónico. De la más antigua a la más nueva traemos al texto y la microbióloga Dra. Ruth Leavitt (Kate Reid) de Andromeda Strain (La amenaza de Andrómeda, Robert Wise, 1971); la astrofísica Eleanor Arroway (Jodie Foster) de Contac (Contacto, Robert Zemeckis, 1997), y a la lingüista Louise Banks (Amy Adams) de Arrival (La llegada, Denis Villeneuve, 2016). Hacemos esta selección acotada a "la cuestión espacial-extraterrestre" y tomando películas de diferentes momentos históricos para luego ocuparnos de sus diferencias y recurrencias. No ofreceremos una sinopsis completa sino pautas que entusiasmen, ya que recomendamos efusivamente su visionado. 
En esta selección sabemos que omitiremos varias otras mujeres científicas heroínas de ciencia ficción: la Dra. Ryan Stone (Sandra Bullock) de Gravity (Gravedad, Alfonso Cuarón, 2013); la bióloga Lena (Natalie Portman) de Aniquilación (Annihilation, Alex Garland, 2018); Murph Cooper (Jessica Chastain) de Interstellar (Interestelar, Christopher Nolan, 2014); y la paleontóloga Kate Lloyd (Mary Elizabeth Winstead) de The thing (La cosa, Matthijs van Heijningen, 2011), y algún puñadito más. Sin embargo, la elección no es caprichosa y lo explicaremos más abajo.

La amenaza de Andrómeda (Robert Wise, 1971). Tras estrellarse un satélite del gobierno de los Estados Unidos en una ciudad de Nuevo México, casi todos los habitantes mueren rápidamente. Se sospecha que el satélite ha traído a la Tierra un microorganismo extraño y letal, y los militares activan un equipo de élite científica para investigarlo. Parte de este equipo será la Dra. Ruth Leavitt. La microbióloga, se presenta como un personaje desafiante, primero ante la autoridad que la recluta para la misión, luego hacia los demás compañeros de equipo. Esta científica fastidiosa y rebelde para acatar órdenes, hace su trabajo a la par de los hombres y sus opiniones son escuchadas atentamente por sus colegas. Ella será la que descubra y demuestre el tipo de crecimiento del organismo nocivo, la pauta para contenerlo.

El guionista Nelson Gidding sugirió el cambio a Wise, quien al principio no era entusiasta, ya que imaginó al Dr. Leavitt como un personaje mayormente decorativo [...]. Finalmente, Wise llegó a estar muy feliz con la decisión de hacer de Leavitt una mujer, ya que la Dra. Leavitt de Kate Reid resultó ser, en sus palabras, "el personaje más interesante de la película". (Javier, 2017, p.4)

Contacto (Robert Zemeckis, 1997). La doctora Ellie Arroway abre el camino a las mujeres científicas protagonistas propiamente dichas: es una exploradora sin miedo a lo desconocido cuyo propósito principal es establecer "contacto". En su labor como integrante del proyecto SETI recibe una secuencia de números primos proveniente del espacio. Los gobiernos de todo el mundo colaboran para construir una máquina-nave que permita la reunión con los seres trasmisores de estas señales, y ella será su tripulante.

Sus ojos -literal y simbólicamente- son el eje de la película. Se nos cuenta su infancia, la relación con su padre. Se la define como brillante, "la jefa" del equipo de investigación. La cinta exhibe, de manera bastante realista, el trabajo de una científica valiente, inteligente y decidida, cuyos esfuerzos suelen ser menospreciados en un campo dominado por hombres. Es ignorada, cuestionada y ridiculizada por colegas, políticos y religiosos, y aún así continúa firme en sus creencias. Si bien la película está más instalada en explicitar discusiones entre ciencia y religión, no por eso deja de presentarnos una mujer con quien podemos identificarnos.

La llegada (Denis Villeneuve, 2016). Doce naves extraterrestres llegan a la Tierra y es necesaria la intervención de una reconocida traductora, la lingüista Louis Banks. Los descubrimientos que logra con respecto a la forma de comunicación de los cefalópodos son fruto de su experiencia y su trabajo. Por supuesto que no puede revelar todo sola, porque 
Jeremy Renner que interpreta a Ian Donnelly (físico teórico) algo tiene que hacer. Así, de paso, se estable la disputa entre ciencias duras y blandas.

Interesante organización narrativa que nos plantea desde el comienzo que memoria, tiempo y orden están interconectados. Hay que aclarar que la película está contada desde el punto de vista de Louise, y será ella quién comience a vivenciar imágenes que los espectadores comprendemos como flashbacks cuando en realidad son flashforwards. Como se nos había anticipado, el tiempo no es lineal y ese es el regalo de los visitantes. Ella logra traducir el concepto, y "traerá" desde el futuro mensajes, informaciones, para emplearlas en el presente y salvar el mundo. Como nota al pie política y anacrónica para una película del año 2016, es que "detrás del muro" están los belicosos a quienes no les importa que el mundo vuele por los aires. China y Rusia, esgrimen sus posiciones más duras.

Hay algunas diferencias fundamentales entre las representaciones de la mujer científica en las películas seleccionadas, una de ellas será seguramente el protagonismo del rol. Sin embargo, la recurrencia más evidente será el grado de centralidad otorgado a su experticia. Estos personajes femeninos despliegan su capacidad intelectual e incluso sus introversiones se colocan en primera línea, haciendo que el filme "se detenga" para verlas pensar, reflexionar, calcular. Vale decir también, que estos personajes femeninos -sin duda mujeres atractivas- no hacen de su apariencia su cualidad principal, ni se sirven de ella para alcanzar sus objetivos.

No sucede lo mismo con otras películas del género donde no será primordial para el desarrollo de la trama las capacidades científicas de las mujeres. Sí es verdad que muchas se erigen en personajes heroicos, pero su destreza pasa por sus aptitudes físicas y valentía para superar obstáculos, enfrentamientos, situaciones problemáticas, etc., más que por su preparación profesional o intelectual.

Flicker (2003, citada por Bañuz y Carmona, 2019) realiza una revisión de las representaciones de la mujer científica en el mainstream entre 1929 y 1997. Si bien hay categorías comunes con los estereotipos científicos más propensos a varones -a los que hemos destinado un apartado-, son significativas las diferencias. Según la autora pueden clasificarse en los siguientes:

- La "vieja solterona" es un personaje que vive su inteligencia como un impedimento para desarrollarse emocionalmente. En este arquetipo feminidad e inteligencia están enfrentadas. - La "mujer masculina" - de costumbres poco saludables y mayormente asexuada-. Su acercamiento al trabajo científico es más emocional que el del resto de sus compañeros hombres y acabará siendo fundamental para la resolución del argumento. (Dra. Ruth Leavitt en La amenaza de Andrómeda).

- La "ingenua experta" es una mujer atractiva que representa una autoridad en su campo científico, pero cuya ingenuidad la mete en problemas de los que solo saldrá gracias al socorro de un personaje masculino. (Los personajes femeninos de la saga Parque Jurásico). - La "conspiradora malvada" es completamente egoísta y usa su atractivo sexual para engañar a su enemigo, que es habitualmente el protagonista masculino. (La Dra. Schneider de Indiana Jones y la última cruzada).

- La "hija" o "asistente", anclada en una relación con un científico hombre de más fama o popularidad. Sacrifica sus capacidades intelectuales para hacer de puente entre "el genio" 
y el resto del mundo. Frecuentemente imprime un necesario elemento emocional. (Murph Cooper de Interestelar).

Flicker (2003 citada por Bañuz y Camona, 2019) añadiría una sexta categoría a partir de Contacto y el personaje de Jodie Foster: la "heroína solitaria".

Una mujer que sobrepasa a sus colegas en conocimientos intelectuales y también en capacidad intuitiva pero que, sin embargo, aún no disfruta del reconocimiento profesional y no puede desprenderse de ciertas dependencias con respecto a un mentor, a un colega o a un superior del sexo masculino. (Bañuz y Carmona, 2019, p.87)

También podría aplicarse a Amy Adams en La llegada.

El cine clásico se constituye sobre dos placeres: el placer voyeurista de mirar al otro como objeto, y el placer narcisista de identificarse con un ego ideal (Mulvey, 1975 citada por Bañuz y Carmona, 2019). Generalmente "ese otro" objetivado es una mujer, "que existe en el cine clásico para ser vista, expuesta como objeto sexual tanto para el espectador como para los personajes masculinos de la narración" (Mulvey, 1975 citada por Bañuz y Carmona, 2019, p.88). Por otro lado, el ego ideal sobre el cual el cine potencia la identificación narcisista es habitualmente masculino, ya que "la narración propicia el papel del hombre como parte activa que despliega la trama” (ibíd.).

En este sentido, la "heroína solitaria" desarrollada por los personajes de Jodie Foster y Amy Adams subvierten su posición como objetos de deseo: no están ahí para ser miradas ni por su sex-appeal, guían activamente el argumento por medio de sus acciones, y estas acciones se basan en la inteligencia. Luchan por el reconocimiento como expertas, y triunfan. Es decir, pareciera como si desde Contacto "la cuestión acerca del desarrollo profesional de la mujer hubiese evolucionado hacia una situación más igualitaria o satisfactoria" (Bañuz y Carmona, 2019, p.88). A su vez, el espectador se identifica con ellas, no solamente porque las películas están contadas desde sus perspectivas, sino por sus cualidades. Ellas personifican lo que admiramos, lo que queremos ser.

"La presencia de mujeres científicas como protagonistas en algunos filmes contemporáneos ha puesto en circulación una visión más optimista de la ciencia y del progreso que la lanzada por sus homólogos masculinos" (ibíd., p.89). Una concepción más cercana al diálogo y al entendimiento, un modelo que conlleva múltiples dimensiones y aspectos, enriqueciendo, además, la representación de la práctica científica.

No obstante, también somos conscientes de que no todas las películas han abandonado una perspectiva convencional, y la mujer científica aún conserva ciertas dependencias con respecto a personajes de sexo masculino (Bañuz y Carmona, 2019). Sin embargo, nos seduce pensar que La llegada y Contacto abren y marcan el camino a seguir hacia una ciencia-ficción con personajes femeninos poderosos y complejos, con mayores precisiones sobre lo que es "hacer ciencia", colocando al científico al servicio de la comunicación rompiendo con los patrones predominantes anteriores. 


\section{Salando las heridas}

Lo que provoca pánico es que el virus escapa a nuestro saber: no lo conoce la medicina, no lo conoce el sistema inmunitario. Y lo ignoto de repente detiene la máquina. Un virus semiótico en la psicósfera bloquea el funcionamiento abstracto de la economía, porque sustrae de ella los cuerpos. ¿Quieren verlo? (Berardi, 2020, p.37).

Y lo impensable nos pasó, irrefutable, irreversible. Mucha tinta corrió y corre sobre las vivencias individuales y comunitarias, las especulaciones políticas, económicas, sociales sobre lo que nos dejará este relato catástrofe del que fuimos protagonistas en 2020. Basta dar un vistazo a todos los textos que circularon desde los primeros meses: Sopa de Wuhan (Amadeo, 2020), La fiebre (Svampa et al., 2020), El futuro después del COVID-19 (Follari et al., 2020). Apuestas, proyecciones, novedades metafóricas como el "virus semiótico" o el "Leviatán sanitario". Zizek con su teoría del final de Kill Bill II, la "Técnica del corazón explosivo de la palma de cinco puntos" contra el sistema capitalista mundial. Byung-Chul Han y la vigilancia digital por parte del Estado -casi de corte orwelliano- donde "no hay ningún momento de la vida cotidiana que no esté sometido a observación" (Han, 2020, p.100) y en donde, según él, radica la mejor contención del virus en Asia que en Europa. Pero como este es un texto sobre cine de ciencia ficción, y los virus siempre han sido muy buenos clientes del género (Lehoucq y Steyer, 2020, citados por Coustal, 2020), creemos pertinente unas líneas para aquellas películas que definimos con un cariz "premonitorio". Las abordaremos sin pretender profundidad sino desde la empatía, desde una catarsis contenida. Cintas que se nos presentaron como un anuncio, una advertencia de la pesadilla que estaba latente. Vamos a ir de la más antigua a la más reciente, y si bien no desconocemos la producción de series televisivas más actuales -y los filmes y telefilmes próximos a estrenarse- decidimos traer al escrito estos clásicos de la pantalla grande.

Por su alcance como medio de comunicación de masas, y por su faceta creativa tanto a nivel narrativo como técnico, el cine es una forma trascendental que tienen las sociedades contemporáneas de mirarse a sí mismas. Así, el análisis de las representaciones [...] de las epidemias, constituye una fuente de información inestimable sobre nuestra forma de entenderlas, experimentarlas y gestionarlas. (Tabernero Holgado y Perdiguero-Gil, 2011, p.45-46)

Epidemia (Wolfgang Petersen, 1995). Un brote viral similar al ébola surge en Zaire en 1967. El ejército decide bombardear la aldea afectada y sanseacabó. Pero el virus resiste, vuelve 30 años después y se traslada a territorio estadounidense. La construcción narrativa nos va revelando que es altamente peligroso, requiere máxima seguridad para su tratamiento y se desconoce la vacuna. Los síntomas son una fiebre hemorrágica que consume el cuerpo en pocos días. Hace su aparición un equipo de expertos bastante desorientado, y que a pesar de cometer todas las torpezas habidas y por haber -rasgan los trajes de protección; las muestras les estallan en la cara; sufren ataques de pánico y se quitan las mascarillas, y hasta se pinchan con agujas infectadas- logran descubrir el antivirus reciclando 
una fórmula escondida, atrapar al monito agente de transmisión e impedir que el ejército bombardee el poblado asolado.

Algunas cuestiones sobre la heroína de esta película interpretada por Rene Russo, que si bien lidera su propio equipo termina colaborando bajo las órdenes de su ex marido. De hecho, su ex marido le salva la vida.

En retrospectiva, podemos percibir algunos componentes que nos interpelan: el virus muta, la cuarentena en las casas, los centros de concentración de infectados, los hospitales atestados, las resistencias a respetar el cierre de fronteras. La televisión es la que guía a la población ante la ausencia total de un Estado de contención como sucedió en muchos países. El virus es contagiado por un animal -un mono-, y sobre el final de la película un mensaje ecológico en relación a la desforestación, lo peligroso de la acción del hombre sobre la naturaleza.

Contagion (Steven Soderbergh, 2011). Esta película es más cercana y por eso más escalofriante. Nos recuerda síntomas de tos, gripe, fiebre, malestar en la garganta, dolor de cabeza. La influencia de los vuelos internacionales en toda la debacle. Tocar cualquier cosa contagia -vasos, picaportes, botoneras de ascensor, etc.- ya que el virus se instala en las superficies. A los pocos días, el infectado muere. El cotidiano se va desarmando y el desguace es inminente, sorpresivo, mientras los números de enfermos van creciendo. Las recomendaciones de los expertos incluyen tomar distancia de otras personas, no tocarse la cara, lavarse las manos con frecuencia o con alcohol en gel. Se instala la cuarentena estricta, mientras los cadáveres se apilan en fosas comunes. Las calles están vacías, se emplazan santuarios con las fotos de los muertos. Los camiones del ejército reparten comida. Se realiza la limpieza de espacios públicos con desinfectante. Las farmacias y los hospitales están colapsados, se improvisan enfermerías en estadios deportivos. El virus viene de Hong Kong y un murciélago es el trasmisor. Vemos comunicadores por los medios que apuntan a conspiraciones o promocionan medicamentos de dudosa eficacia. Se hace referencia a la gripe española y al SARS como antecedentes. La resolución de la pandemia lleva -más o menos- 133 días, momento en el cual comienza el sorteo de la vacuna.

Y la científica interpretada por Jennifer Ehle, descubre el antiviral de modo muy poco profesional desconociendo todos los protocolos. Lo prueba en sí misma y se expone a la enfermedad esperando lo mejor.

Virus (Sung-su Kim, 2013). Ambientada en el año 2014, la película nos informa que está basada en eventos reales. Un virus es transportado a una ciudad cercana a Seúl desde Hong Kong. Los síntomas incluyen fiebre alta, y explícitamente las partículas de saliva que se exhalan al toser generan el contagio instantáneo. El transporte público, los comercios, las escuelas son espacios de transmisión. Se da intervención a un equipo de expertos, que si bien no logra identificar el virus, lo asocia con la gripe aviar. Los hospitales rápidamente se atiborran de pacientes. Las decisiones políticas no son las más acertadas, en una primera instancia el gobierno se niega a aislar la ciudad ante "un brote de gripe". Al ir avanzando la cantidad de infectados, se cierran fronteras, aeropuertos, centros comerciales.

Se establecen rápidamente zonas de concentración de casos que están divididas en dos sectores. Uno, para quienes deben esperar $48 \mathrm{hs}$. el resultado del PCR; otro, dedicado a los 
declarados enfermos. Los protagonistas descubren que en realidad para los enfermos no hay tratamiento, los cuerpos son incinerados -incluso sin confirmar la muerte-. Mientras tanto, el gobierno reconsidera y un asesor estadounidense propone bombardear la ciudad antes de que la infección llegue a Seúl, e incluso se extienda a otros países. El nuevo presidente -nombrado durante la emergencia- no acuerda con la "solución final". El panfleto político incluye que si EEUU decidiera enviar aviones, Corea está preparada para bajarlos en pleno vuelo.

Con importantes momentos melodramáticos, la heroína científica interpretada por Soo Ae, doctora reconocida y parte del consejo asesor, transfunde a su hija enferma con la sangre del paciente cero de modo clandestino. Ella y la nena son recluidas, pero no duda en escapar arriesgando a todos los que la rodean.

"Si la ciencia ficción tiene una utilidad [...] es tratar de ver basándose en el presente qué puede pasar en el futuro y decir: ¡cuidado!” (Andrevon, 2020 citado por Coustal, 2020). Así, nos resultaba interesante recuperar estas miradas del cine, ya que comprendemos que "las epidemias cinematográficas permiten explorar muy diferentes aspectos en relación con la enfermedad y la muerte, no sólo a un nivel estrictamente médico-sanitario, incluyendo sus componentes demográficos, económicos, políticos y culturales, sino también a nivel físico y emocional" (Tabernero Holgado y Perdiguero-Gil, 2011, p.46).

Las tres películas responden a una combinatoria que determinan el grado de dramatismo de la narración: la proximidad espacial y temporal; la velocidad y el nivel de mortalidad del virus; la descripción/construcción sobre cómo se ven afectados en pocos días los cimientos de la sociedad, y el grado de estigmatización de los infectados. Las enfermedades, en este caso las epidemias "resultan muy atractivas para el cine de ficción por su poder dramático [...] y en tanto que metáforas del mal" (Tabernero Holgado, Perdiguero-Gil, 2011, p.46). Sin embargo, con todo el arsenal de su estrategia narrativa y puesta en escena, no logran graficar lo que vivimos. Ni al más trasnochado de los guionistas se le ocurrió la posibilidad de contagio previa a los síntomas, que el virus se resista y no pueda cercarse desde hace más de un año, las precauciones que no parecen suficientes, el temor hacia los nuevos rebrotes, las idas y venidas desde las políticas públicas sanitarias a nivel global, que la terapia intensiva pueda durar decenas de días taponando la disponibilidad de camas, que las vacunas no alcancen y además se discuta su efectividad.

Aún así, todas ellas anuncian una regeneración, un nuevo comienzo o "nueva normalidad", la victoria individual y colectiva. Un mensaje esperanzador que nos hace mucha falta, donde ojalá sea allí donde se encuentre su rasgo de presagio.

\section{Reflexiones finales}

"Los efectos de lo que vendrá son incalculables. Inasibles, porque la experiencia previa no nos permite hacer una estimación con la cual poder sobrellevar lo angustiante de la incertidumbre. Y con esto contamos. Con nada" (Méndez, 2020, p.250).

Pudimos recorrer a lo largo de los diferentes apartados, algunas ideas en torno a las relaciones entre géneros cinematográficos y literarios, y cómo la ciencia ficción desde los 
albores del cine ha ido ganando un lugar preeminente en las pantallas. También la hemos caracterizado por su versatilidad para adaptarse a los devenires sociohistóricos, lo que le proporcionaría una proyección casi ilimitada.

La ciencia ficción -junto con el género de acción y el western-, tal vez sea el producto cinematográfico más masculinizado: protagonizado por hombres y dirigido a hombres. Al mismo tiempo, muchas veces, ofrece una visión completamente estereotipada de los científicos y su práctica. Así, establecimos algunos lugares comunes dedicados a los científicos y científicas, y nos detuvimos en aquellas películas que han reducido a la mujer a objeto-creación, pero también en aquellas que las valoraron como sujetos activos, valientes, inteligentes, excelentes en su campo.

Creemos que el cine recoge el sentido colectivo de las manifestaciones políticas, sociales, económicas y culturales de un determinado momento que se representan en sus imágenes.

Desde su nacimiento a finales del siglo XIX, el cine se ha convertido en uno de los principales conformadores del imaginario colectivo, [...] y jugado un papel fundamental a la hora de definir los estereotipos y roles de género, casi siempre desde un punto de vista masculino, en especial en el género de ciencia ficción. El cine se ha puesto al servicio de la ideología dominante para construir una serie de significados, nada neutrales que gracias a la especificidad del medio, se nos hacen pasar por naturales y contribuyen a perpetuar la dominación de las mujeres. (Cruzado Rodríguez, 2009, p.9)

Debemos ser conscientes de que el cine -junto con otros medios de comunicación-, sienta las bases del pensamiento de la sociedad en su conjunto. Recrea un mundo simbólico a través del cual se generan los significados desde los que pensamos y sentimos. En este sentido funciona su importancia en la construcción/transmisión de valores. "Crecemos y nos formamos viendo series y películas, con ese personaje al que idolatramos desde pequeños o esa película que nos remueve por dentro" (Gómez González, 2019, p.4). Con ello, el cine y la ciencia ficción en tanto género superlativamente popularizado, contribuye de manera importante al proceso de socialización: cómo es y qué hace -o qué puede hacer- una mujer, cómo es y qué hace un hombre. Es en estas formas de expresión que se visibilizan identidades, conflictos, disputas de poder, y también, afortunadamente, pueden comenzar a esculpirse transformaciones.

Si bien la masculinidad hegemónica sigue siendo canon, parece que los personajes dedicados a las heroínas científicas de ciencia ficción comienzan a diversificarse, irse ajustado a los cambios sociales. Estas heroínas, además, nos ofrecen una versión más optimista de la ciencia puesta al servicio del diálogo y la comunicación, y bastante más precisa sobre la práctica. Es decir, han aportado humanidad a los estereotipos clásicos. Pero aún necesitamos más heroínas cinematográficas, investigadoras tenaces, profesionales de excelencia, y mujeres cineastas, directoras y guionistas, que las materialicen. Esperanzadoramente, y siguiendo este hilo de pensamiento, muchas niñas van a crecer identificándose con estas emergentes heroínas de la sci-fi. El cambio no ha hecho más que empezar.

Un último párrafo a modo de cierre, para recuperar el contacto constante que propusimos a lo largo de este escrito con La Pandemia -con mayúsculas-. En todo el mundo la catás- 
trofe sanitaria ha marcado un retroceso para varios derechos sociales, entre ellos la carrera por cerrar la brecha de género, la persecución de la igualdad entre hombres y mujeres. El deseo es que podamos reconstruirnos en un nuevo comienzo, haciendo eco del presagio de las películas de ciencia ficción más distópicas que, generalmente, anuncian una regeneración. Porque después de todo, el coronavirus también "nos arroja al gran ruedo en el cual importan sobre todo los grandes debates societales; cómo pensar la sociedad de aquí en más" (Svampa, 2020, p.18).

\section{Bibliografía}

Acosta Jiménez, W. (2018). El cine como objeto de estudio de la historia: apuestas conceptuales y metodológicas. Folios, (47), 51-14.

Aldiss, B. W. (1973). Billion year spree: The true history of science fiction. New York: Doubleday.

Altman, R. (2000). Los géneros cinematográficos. Barcelona: Paidós.

Amadeo, P. (ed.) (2020). Sopa de Wuhan. Pensamiento Contemporáneo en tiempos de pandemias. Buenos Aires: ASPO.

Berardi, F. (2020). Crónica de la psicodeflación. En Amadeo, P. (ed.), Sopa de Wuhan. Pensamiento Contemporáneo en tiempos de pandemias (pp. 35-55). Buenos Aires: ASPO.

Bañuz, C. y Carmona, M. A. (2019). Perfectas para el papel: Representaciones de las mujeres científicas en la ciencia-ficción contemporánea. En Llibre d'actes Congrés Dones, Ciència i Tecnologia (pp.80-92). Barcelona: Omnia Publisher SL.

Bilbao, B. (2020). Nuevo hábitat. En Svampa et. al, La Fiebre (pp. 187-199). Argentina: ASPO.

Cambra Badii, I. (2018). Pensar el cine. La narrativa de películas y series como matriz metodológica para el tratamiento de problemas complejos. PROMETEICA - Revista de Filosofía y Ciencias, (17), 62-76.

Christidou, V. (2011). Interest, attitudes and images related to science: Combining students' voices with the voices of school Science, teachers, and popular science. International Journal of Environmental \& Science Education, 6(2), 141-159.

Coustal, L. (2020). Ciencia ficción y las grandes epidemias. Chicago Tribune. Disponible en https://www.chicagotribune.com/espanol/sns-es-ciencia-ficcion-premonitoria-grandespandemias-coronavirus-20200504-g5bf7yupgrbgxf4442qm3tweri-story.html Fecha de consulta 10/01/2021.

Cruzado Rodríguez, A. (2009). Mujeres de cine: discurso patriarcal y discurso feminista de los textos a las pantallas. (Tesis doctoral) Universidad de Sevilla. Sevilla, España.

Del Molino García, R. (2003). El Discurso Del Miedo Apocalíptico y Sus Representaciones Cinematográficas Durante La Guerra Fría. Comunicación y Ciudadanía, (6), 6-15.

Dos, M. (2010). Almas de metal: la mujer como creación científica en el cine. Dossiers feministes, (14), 20-33.

Freixas, R. y Bassa, J. (1993). El cine de ciencia ficción. Barcelona: Paidós.

Follari, R., Canelo, A., Vera, P., Sztulwark, D.; Palermo, V. A.; González, H. (2020). El futuro después del COVID-19. Argentina: Jefatura de Gabinete de Ministros. 
Gómez González, S. (2019). De Ellen Ripley a Capitana Marvel: análisis del papel de la mujer en el cine de ciencia ficción. (Tesis de grado). Universidad de Sevilla. Sevilla, España.

Gilks, M. y Allen, M. (2003). The Subgenres of Science Fiction. Writing world. Disponible en https://www.writing-world.com/sf/sf.shtml Fecha de consulta: 24/01/2021

Han, B. (2020). La emergencia viral y el mundo de mañana. En Amadeo, P. (ed.), Sopa de Wuhan. Pensamiento Contemporáneo en tiempos de pandemias (pp. 97-113). Buenos Aires: ASPO.

Haynes, R. (2003). From alchemy to artificial intelligence: stereotypes of the scientist in Western literatura. Public Understand. Sci, (12), 243-253.

Javier, F. (2017). Para que no me olvide. Disponible en http://paraquenomeolvide2.blogspot. com/2017/12/andromeda-y-su-amenaza.html Fecha de consulta: 24/12/2021

Jermyn, D. (2005). The Rachael Papers: In Search of Blade Runner's Femme Fatale. En Brooker, W. (ed.), The Blade Runner Experience, (pp. 159-173). London: Wallflower.

Levin, L. y Kreimer, P. (2012). Las dimensiones sociales de la ciencia en el cine. Ciencias 106-106, (enero junio 2012), 130-139.

López, M. P. (2020). La vida en cuestión. En Svampa et. al, La Fiebre (pp. 69-79). Argentina: ASPO.

Méndez, L. (2020). No volvamos a la normalidad. En Svampa et. al, La Fiebre (pp. 243-253). Argentina: ASPO.

Menéndez, A. y Medina, R. (2011). Cine, Historia y Medicina. En A. Casado da Rocha y W. Astudillo (ed.), Cine y medicina en el final de la vida (pp. 56-67). San Sebastián: Sociedad Vasca de Cuidados Paliativos.

Merás, L. (2013). Replicantes o sumisas: El cyborg femenino desde Blade Runner. Sesión no numerada: Revista de letras y ficción audiovisual, (4), 7-33.

Monroy, N. (2008). Cine y literatura de ciencia ficción, perspectivas teóricas. (Tesis doctoral). Universitat Autónoma de Barcelona, Barcelona, España.

Moreno Lupiañez, M. (2003). Cine y Ciencia. Quark: Ciencia, medicina, comunicación y cultura, (28), 102-111.

Olagüe, R. (2018). Análisis audiovisual de las masculinidades del cine de ciencia ficción de masas. (Tesis de grado). Universidad pública de Navarra, Pamplona, España.

Pasquinelli, L. (2020). Lo local es político. En Svampa et. al, La fiebre (pp.169-187). Buenos Aires: ASPO.

Pedraza, P. (2001). La amante mecánica (Vanguardia y máquina). Trama y fondo: revista de cultura, (11). Pedraza, P. (2009).El regreso de la mujer muerta. Dossiers Feministes, (13), 45-50.

Rodríguez Alzueta, E. (2020). Las trampas de la unidad. En Svampa et. al, La fiebre (pp.7989). Buenos Aires: ASPO.

Svampa, M. (2020). Reflexiones para un mundo post-coronavirus. En Svampa et. al, La Fiebre (pp.17-39). Argentina: ASPO.

Svampa, M., Cragnolini, M., Ribeiro, S., Aizen M., López, M. P., Rodríguez Alzueta e.,... Petruccelli, A. (2020). La Fiebre. Buenos Aires: ASPO.

Tabernero Holgado, C. y Perdiguero-Gil, E. (2011). El cine y las dimensiones colectivas de la enfermedad. Rev Med Cine, 7(2), 44-53. 
Valderato, S. (2020). El virus es el mensaje. En Follari et. al, El futuro después del COVID-19 (pp. 151-156). Argentina: Jefatura de Gabinete de Ministros.

\section{The path of the heroines in times of science fiction}

Abstract: 2020 wasn't our best year. We never had lived in a global quarantine, we never had seen the strongest countries so vulnerable, we never had feared in such a desperate way for our loves ones. We face the COVID-19: the "Invisible Enemy". From overnight we crashed into a science fiction scenario. The foreboding in Flu (Sung-su Kim, 2013), Contagion (Steven Soderbergh, 2011) and Outbreak (Wolfgang Petersen, 1995) became real. The fear of death and sickness escaped from "silver screen" and the world changed forever. It was science fiction -aside from fantasy stories- that fed their plots from the panic of invasion, hunger, contagion, consequences of nuclear activity, bombing, unexpected catastrophes. All stories in which death no longer awaits "the end of life rushes by proximity" (Rodríguez Alzueta, 2020, p.81). Such as other film genres and subgenres, it found its origins in literature, and the first work known as such is Frankenstein, a novel written by a woman (Aldiss, 1973). With the arrival of film industry, the love crush was immediate. Since Le Voyage dans la Lune (Georges Méliès, 1902) science fiction established itself in the big -and small-screen and won't stop expanding and diversifying.

However, it must be said that representation of the scientific practice has not been one of the most favored by cinema. The treatment of techno-science "seems to give writers and directors a sort of letter of marque that often present an image of science that looks nothing true" (Moreno Lupiáñez, 2007, p.1). And there show up stereotypes like the "evil alchemist", the "clueless genius", or the "mad, bad and dangerous scientist" (Haynes, 2003). If this is the recurring image of the man dedicated to science, what's left for women in a genre where "masculinity" has had a privileged place? Filmakers and movies of all ages, starting with Fritz Lang and his automata in Metropolis (1927), going into The Stepford wives (Frank Oz, 2004), even Blade Runner (Ridley Scott, 1982) and many more examples, have fascinated in presenting women as a scientific creation, "a proper fantasy of a patriarchal society that dreams with subduing women to men's rules" (Dos, 2010, p.32). Difficult will be the search for women with a leading role, where their discoveries come from their intellect, as banners of mathematical, physical, medical solutions. Women as a symbolic subject, not as an object.

"During the 20th century, film became a media that broadcasted values, behaviors, ideology and stories about urban society and modernization of cultures, with the capacity to influence our feelings and thoughts" (Acosta Jiménez, 2018, p.52). With this premise present and understanding film as document, a place of the memory and the collective imagination, let us try to approach the different "ends of the world" that the seventh art offered, to reflect on the place of the female hero in science fiction. Because after all, the coronavirus also "throws us in the big ring in which what matters above all are society's great debates; how we think society from here on out" (Svampa, 2020, p.18). 
Keyword: film - science fiction - women as objects - stereotypes of science - foreboding movies - female hero scientists.

\section{O caminho das heroínas em tempos de ficção científica}

Resumo: 2020 não foi o nosso melhor ano. Nunca vivemos num estado de quarentena global, nunca vimos os países mais ricos tão vulneráveis, que nunca tememos tão insistentemente pelos nossos entes queridos. Somos confrontados -continuamos nessa batalha - com o COVID-19: o "inimigo invisível". Da noite para o dia naufragamos num palco de ficção científica. A natureza premundo do vírus (Kim Sung assim, 2013), Contagion (Steven Soderbergh, 2011) e Epidemia (Wolfgang Petersen, 1995) tornaram-se carne. O medo da morte e da doença escapou da "tela de prata" e o mundo mudou para sempre.

Foi a ficção científica -independente da história fantástica- que ao longo da história foi alimentada pelo pânico à invasão, à fome, ao contágio, às consequências da atividade nuclear, dos bombardeamentos, das catástrofes inesperadas. Todos os relatos onde a morte já não aguarda "no fim da vida, mas corre por proximidade" (Rodríguez Alzueta, 2020, p.81). À semelhança de outros géneros e subgéneros cinematográficos, encontrou a sua origem na literatura, e vale a pena notar que a primeira obra reconhecida como tal é o romance de Frankenstein escrito por uma mulher (Aldiss, 1973). Com o advento do cinema, a paixão foi imediata. Desde le Voyage dans la Lune (Georges Mélias, 1902) a ficção científica estabeleceu-se no grande ecrã - e menina - e continua a expandir-se e a diversificar.

No entanto, é preciso dizer também que a representação da prática científica não tem sido das mais estragadas pelo cinema. O tratamento da tecnociência "parece dotar os roteiristas e diretores de uma certa letra da marca para apresentar, muitas vezes, uma imagem da ciência que não corresponde à realidade" (Moreno Lupiáñez, 2007, p.1). E aí os estereótipos do "alquimista aprendiz de feiticeiro", do "gênio sem noção", ou do desfile do "cientista louco, mau e perigoso" (Haynes, 2003).

Se esta é a imagem recorrente do homem dedicado à ciência, o que restará para as mulheres em um gênero em que "o masculino" manteve um lugar privilegiado? Cineastas e filmes de todas as idades, começando com Fritz Lang e seu autômato em Metrópolis (1927), passando pelas esposas dos Stepford (Frank Oz, 2004), até mesmo Blade Runner (Ridley Scott, 1982) e muitos outros exemplos, ficaram fascinados por apresentar as mulheres como uma criação científica, como "a fantasia de uma sociedade patriarcal que sonha em submeter as mulheres aos ditames dos homens" (Dos, 2010, p.32). A busca difícil será a dos estudiosos investigativos, precisos e objetivos com protagonismo, onde as descobertas são dadas a partir de seu intelecto, como padrões de soluções matemáticas, físicas, médicas. A mulher como sujeito simbólico e não como objeto.

"Durante o século 20, o cinema tornou-se um meio que massificou valores, comportamentos, ideologias e histórias sobre a sociedade urbana e a modernização das culturas, com capacidade de influenciar a configuração do sentimento e do pensamento" (Acosta-Jimenez, 2018, p.52) Com esta premissa em mente e entendendo o cinema como documento, lugar 
de memória e imaginação coletiva, tentaremos nos aproximar dos diferentes "confins do mundo" que a sétima arte nos ofereceu para dimensionar o lugar da ciência. Heroína de ficção. Porque, afinal, o coronavírus também "nos joga na grande arena em que os grandes debates sociais importam acima de tudo; como pensar a sociedade a partir de agora" (Svampa, 2020, p.18).

Palavra chave: cinema - ficção científica - mulheres objeto - estereótipos da ciência filmes pressagiosos - heroínas científicas.

[Las traducciones de los abstracts fueron supervisadas por el autor de cada artículo] 